only sciences which have succeeded in producing immediate conviction and durable results are mathematics and those into which mathematics enters to a very great degree. The biological sciences are more difficult because of their incalculable variables. But we advance none the less, step by step.

When we look back we can be impressed by the ignorance that was our forefathers'. The mathematicians of Elizabethan times were totally igporant of the quantum theory, of nuclear physics, of wave mechanics. That is scarcely 400 years ago. What will they say of us 400 years from now! We are aware of vague discomforts in our minds about so many things. So must they have been. Until we can get our uneasinesses to the point of crisp formulation they admit of no answer, for we cannot investigate them. Let us not therefore laugh too loud at our fathers lest posterity overhears us! Their ignorances were of things that they could not have known; they lacked the interlocking discoveries and precision instrumenis that little by little advance learning. This is implicit in all that $I$ have said of the nervous impulse and the cellular nature of the nervous system and the body. It is true of chemistry, physics, and astronomy.

It was nearly 300 years before instruments of sufficient delicacy were available to confirm the parallax of the fixed stars which the Copernican theory of the earth's motion demanded. It would be absurd to imagine that progress in instrumeniation is a process which has now ceased, that further improvements will not disclose our present ignorances. We can be very sure that there are a dozen things under our noses which we misconceive or do not even see. The greatest source of error lies in our having explanations that satisfy us or with which we make do because we can see no other. That was where our forerunners came to grief, though I deprecate such a manner of expressing it. It is unquestionably where we ourselves shall be found to have erred. Our greatest ignorances must by definition be those of which we are unaware. Wilfred Trotter speaks of our natural resistance to new truths, our battle to throw them off at once because they irritate like an acid or sting. That seems to be particularly so when we are satisfied with what we already know of the subject. When our minds are vacant of explanation we seem to be extraordinarily gullible, ready to accept any theory, however nonsensical.

\section{The Emotions in Science}

Whatever means science theoretically should use, the scientist is a man more imaginative than Bacon would allow or Magendie would admit. He does require a presupposition which it is his intention to investigate. He is in fact a good deal more rational, more emotional, in a word more human, than argument can hold him to be. Hence his scepticism must be wiltul. There have been important scientists who have appeared to maintain a scrupulous exactness in their researches but who have displayed emotion, bias, prejudice, and temper in their pronouncements on other subjects, notably on politics. It is difficult to believe that none of these qualities are to be found in their scientific work. Everything that a scientist does must have a personal flavour and be subject to those vagaries which personality implies. The intellectual cold purity of scientific work, something that is like a flame without heat, is a supposition without possibility of realization. Orderly scepticism is a discipline, not an intuitive possession; the proper name for the intuitive variety is prejudice

There are other large fields of knowledge besides science : there is knowledge to be gained from literature, history: there are the arts : there is philosophy that embraces all kinds of knowledge. In these others the emotional side of men's nature is permitted a freer rein, and in the arts its fullest development is positively demanded. Men cannot lead contented lives unless they store their minds with goods bearing different kinds of trade-mark. There are many who believe that scientific certainty is not the only kind, who would agree with Descartes that they could recognize some ideas as so clear and so distinct that they brought instantaneous conviction and were immediately acceptable as truths. But unless they can be demonstrated, can be shown to be indestructible on attack, they must remain truths only for the individual who holds them. This seems a depressing conclusion, however well it may explain man's permanent liability to disagree with his fellows.

\section{Conclusion}

However, it is, as Glanvil would have said, "more perpendicular to our discourse" to conclude that our task in keeping emotions in control in science is difficult, since they are so permissible in much else that occupies our thoughts, colour our lives, and are at all times ineradicable. The rules that we live by have been made by experience as curbs on unfettered emotional behaviours. The rules of science have a shorter history, but are in the main of the same kind narrowed by a sharper focus to a different end. We have seen that better knowledge of the brain gives us no hope for lenses that will automatically correct the astigmatism of our minds. Let us then live our lives according to rules of historical experience, and in our scientific thinking let them be tempered, but with our actions not paralysed, by scepticism.

\section{THE BACTERICIDAL ACTION OF STREPTOMYCIN}

BY

\author{
LAWRENCE P. GARROD, M.D., F.R.C.P. \\ Bacteriologist to St. Bartholomew's Hospital : \\ Professor of Bacteriology in the University of London
}

Streptomycin, an antibiotic derived from Actinomyces griseus, and discovered by Schatz, Bugie, and Waksman (1944), owes its therapeutic value to action on bacteria which are insensitive to penicillin, notably Myco. tuberculosis and many species of Gram-negative bacilli. The original description credits it with "strong bactericidal properties" without giving evidence for this statement. Several subsequent authors, including Hegarty, Thiele, and Verwey (1945), Hamre, Rake, and Donovick (1946), Strauss (1947), and Smith and Waksman (1947), have shown that low concentrations added to susceptible bacteria in a nutrient medium cause a slow fall in the viable count; it has also been observed that in a non-nutrient medium there is no such effect unless a considerably greater concentration is used. The only published example of a test employing a high concentration in a nutrient medium is an experiment by Helmholz (1945), who inoculated the urine of a patient under treatment with streptomycin and containing 1,330 units (micrograms) per $\mathrm{ml}$. with various bacteria, and found that they were all killed within one hour. Since concentrations of this order can easily be attained in the urine, and local treatment can produce similar conditions elsewhere, it is clearly of interest to know more about their effect on bacteria.

In so far as the action of a chemotherapeutic agent is bactericidal, that action must be influenced by the various factors such as concentration, temperature, medium, and 
inoculum size, which are known to affect chemical disinfection generally. Since there appears to be little information on these points, the following experiments were undertaken to provide it.

Method.-The organism used was Staph. aureus (Oxford $H$ strain), the inoculum being derived from a 24-hour culture in ox-heart-extract peptone broth. The basis of the test mixture was usually the same broth, to which was added streptomycin and such an amount of culture as to give an initial viable count of about $50,000,000$ per $\mathrm{ml}$. Jubes or flasks containing these mixtures were maintained at the desired temperature, usually $37^{\circ} \mathrm{C}$., in a water-bath, and viable counts were performed at intervals, either by the conventional method of pour plates made from decimal 'dilutions or by the surface viable count method (Miles, 1937), which is more economical in medium, and quite accurate enough when large changes in population are taking place.

\section{Bactericidal Action}

\section{The Effect of Concentration}

It is evident from Fig. 1, showing the fall in the viable count over a period of eight hours produced by four different concentrations of streptomycin in broth at $37^{\circ} \mathrm{C}$., that streptomycin is bactericidal. An original population of $95,000,000$ per $\mathrm{ml}$ is entirely extinguished by $20 \mu \mathrm{g}$. per $\mathrm{ml}$. in eight hours, by 50 or $100 \mu \mathrm{g}$. per $\mathrm{ml}$. in four hours,

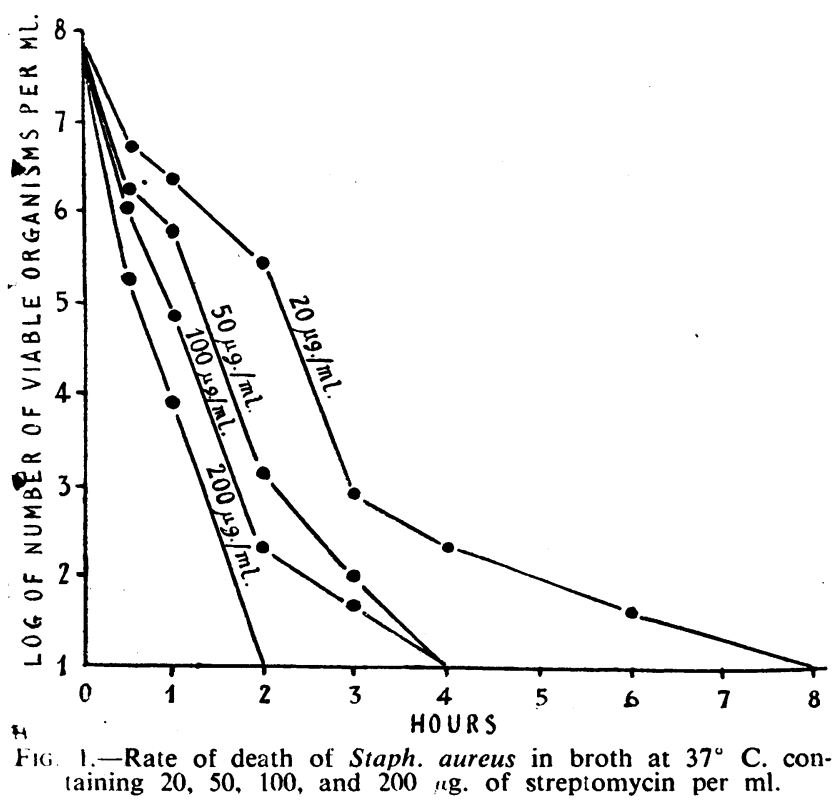

and by $200 \mu \mathrm{g}$. per $\mathrm{ml}$. in two hours. It also appears that the death rate varies with the concentration of the drug; this is still more evident in Fig. 2, in which it should be noted that the time scale covers a period of only two hours. Here a concentration of $200 \mu \mathrm{g}$. per $\mathrm{ml}$. has not quite extinguished a rather larger inoculum within that period, but $2,000 \mu \mathrm{g}$. per $\mathrm{ml}$. has an exceedingly rapid lethal action. Counts made at short intervals, not all of which are plotted on the graph, showed a marked fall within one minute and a mortality of $99.8 \%$ within ten minutes. How soon this mixture was completely sterilized cannot exactly be stated, because cultures made from the first dilution of it contained too much transferred streptomycin to permit growth. It can, however, be stated that the number of survivors per $\mathrm{ml}$. after 20 minutes was less than 5,000 (mortality of over $99.995 \%$ ).

The action of streptomycin thus differs radically from that of penicillin, which is not accelerated by increase in concentration above a minimum level. I found three years ago (Garrod, 1945) that a concentration of 1,000 units of grossly impure penicillin per $\mathrm{ml}$. was actually less rapidly bactericidal than one of only 1 unit per $\mathrm{ml}$, owing presumably to the retarding effect of some impurity. On the other hand, the LT 50 (time required to kill $50 \%$ of

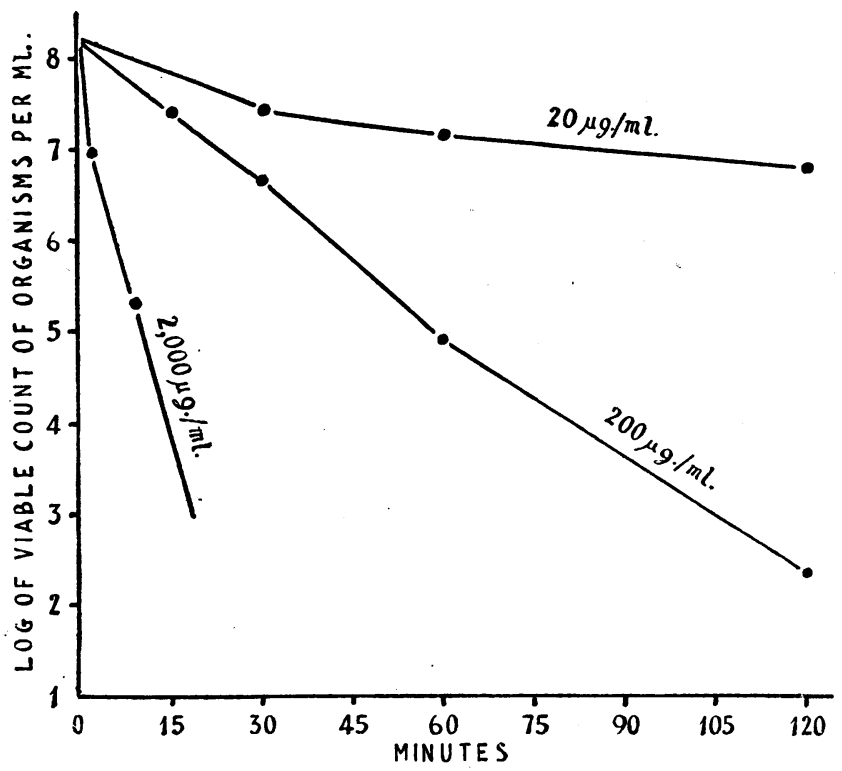

Fig. 2.-Rate of death of Staph. aureus in broth at $37^{\circ} \mathrm{C}$. containing 20,200 , and $2,000 \mu \mathrm{g}$. of streptomycin per $\mathrm{ml}$.

the inoculum) of a sample of $85 \%$ purity-the best then available-was between 100 and 89 minutes for all concentrations tested from 1 to 1,000 units per $\mathrm{ml}$. I have recently repeated this experiment with pure penicillin $G$, and the results are shown in Fig. 3. The fall in the viable count produced by concentrations of $1,10,100,1,000$ and even 10,000 units per $\mathrm{ml}$. is so similar that the graph is too tangled for its individual lines to be labelled or even followed clearly. It will also be noticed that this lethal effect is much slower that that of even moderate concentrations of streptomycin. (It appears in this experiment with pure penicillin $G$ to have been even slower than that usually produced by commercial penicillin. This point has not been further investigated, but if such a difference were found it would be of interest in view of recent observations on the therapeutic inferiority of the pure product.)

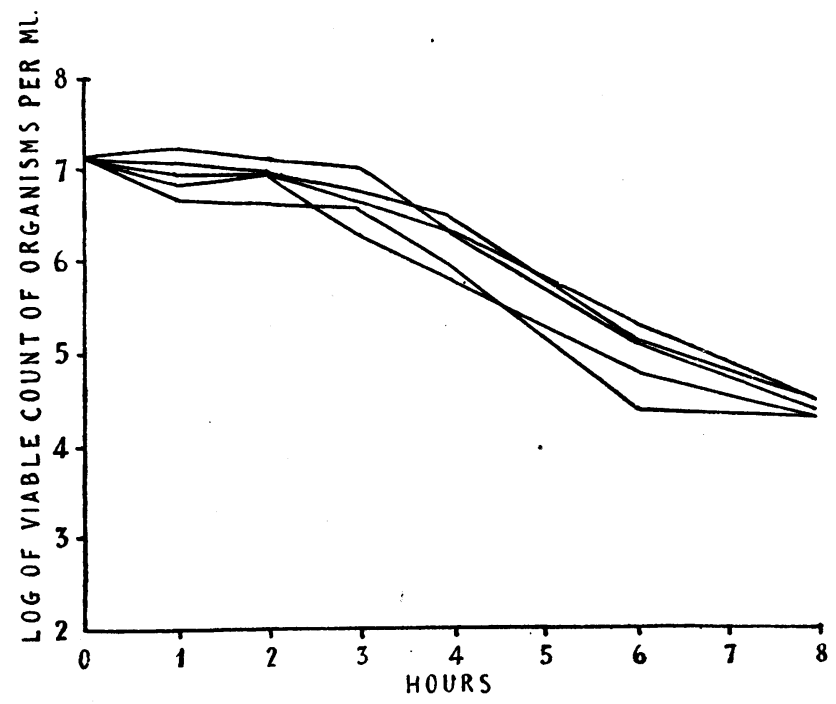

Fig. 3.-Rate of death of Staph. aureus in broth at $37^{\circ} \mathrm{C}$. containing $1,10,100,1,000$, and 10,000 units of pure penicillin $G$ per $\mathrm{ml}$. 
That streptomycin in higher concentrations is rapidly lethal is of practical as well as theoretical interest; an example of the former will be mentioned later.

\section{Effect of Temperature}

All bactericidal action is accelerated by increase in temperature, and streptomyc in forms no exception to this rule. Fig. 4 illustrates the results of an experiment in

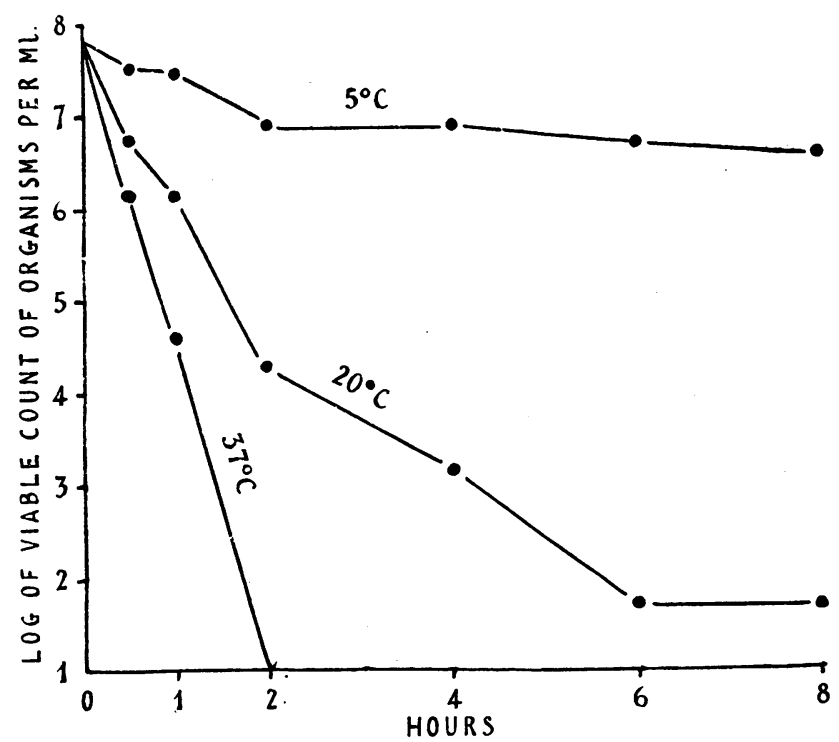

FIG. 4.-Rate of death of Staph. aureus in broth containing $200 \mu \mathrm{g}$. of streptomycin per ml. at $5^{\circ}, 20^{\circ}$, and $37^{\circ} \mathrm{C}$.

which the effect of $200 \mu \mathrm{g}$. of streptomycin per $\mathrm{ml}$. on Siaph. aureus in broth was observed simultaneously at $5^{\circ}$, $20^{\circ}$, and $37^{\circ} \mathrm{C}$.

\section{Effect on Different Species}

The effects observed are not peculiar to staphylococci; Fig. 5 shows the death rate of Bact. coli and Str. pyogenes in comparison with that of Staph. aureus under the same

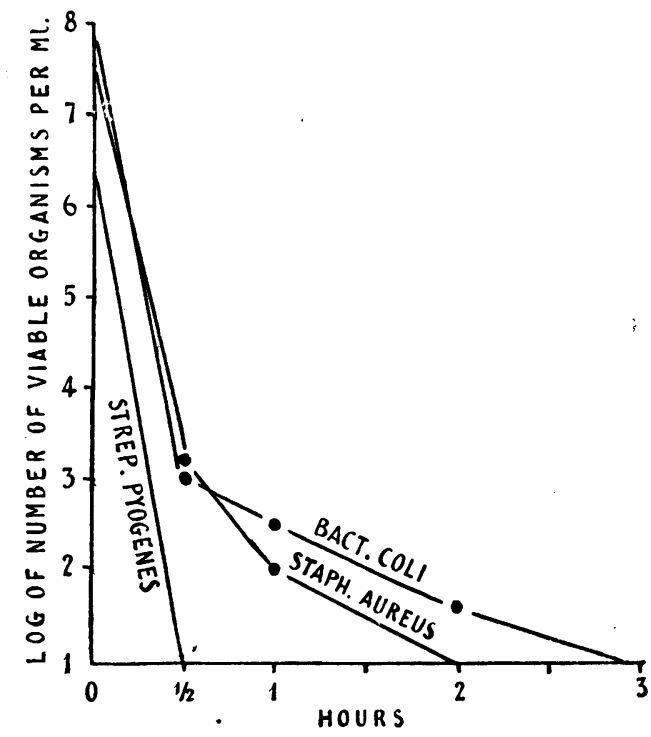

Fig. 5.-Rate of death of three species of bacteria in broth containing $200 \mu \mathrm{g}$. of streptomycin per $\mathrm{ml}$. at $37^{\circ} \mathrm{C}$.

conditions $(200 \mu \mathrm{g}$. of streptomycin per $\mathrm{ml}$. in broth at $37^{\circ} \mathrm{C}$.). Slight differences between the rates of disinfection in this experiment should be disregarded; the susceptibility of different strains within a single species is much more variable than susceptibility to penicillin. It is stated (Report, 1946) that the minimum concentrations of streptomycin required to inhibit growth are $0.5->16 \mu \mathrm{g}$. per $\mathrm{ml}$. for Staph. aureus, $2.0->16$ for Str. pyogenes, and 0.3-3.75 for Bact. coli; the rate of disinfection presumably varies correspondingly, and the behaviour of single strains is therefore not exactly representative of the species as $a$ whole.

\section{Effect of the Medium}

In all the foregoing experiments the medium was broth. In order to determine the effect of other media, broth culture of Staph. aureus was thoroughly washed (centrifuged three times and resuspended in saline); whep such a suspension was added to defibrinated blood or serum containing $200 \mu \mathrm{g}$. of streptomycin per ml. at $37^{\circ} \mathrm{C}$. the rate of fall in the viable count approximated closely to that observed in broth. In urine (sterilized by filtration and adjusted to $p \mathrm{H} \mathrm{7.4)} \mathrm{the} \mathrm{effect} \mathrm{was} \mathrm{similar} \mathrm{but} \mathrm{less} \mathrm{rapid.} \mathrm{On}$ the other hand, washed culture added to saline containing $200 \mu \mathrm{g}$. of streptomycin per $\mathrm{ml}$. was completely unaffected: the viable count, as in the saline control containing no streptomycin, remained almost stationary throughout the eight-hour period of observation.

In view of the finding of Strauss (1947) that higher con-5 centrations are bactericidal even in a non-nutrient medium, this experiment was amplified as follows. The same inoculum of washed Staph. aureus was added to four media. giving an initial viable count of approximately 50,000,000 per $\mathrm{ml}$. In broth containing $200 \mu \mathrm{g}$. of streptomycin per $\mathrm{ml}$. the count fell to nil in cne hour. In saline with or without $200 \mu \mathrm{g}$. of streptomycin per ml. it remained stationary. In saline containing $2,000 \mu \mathrm{g}$. of streptomycin per $\mathrm{ml}$. it fell in 30 minutes to 850,000 , and thereafter fluctuated round this level ; individual colony counts were inconsistent, suggesting that the cells were in a condition in which chance affected their capacity for growth. It thus appears that very high concentrations of streptomycin are incompletely and irregularly bactericidal in a non-nutrient. medium.

In its dependence on a nutrient medium for rapid bactericidal action streptomycin resembles penicillin, but there is a striking difference in their effects. That of penicillin becomes evident only after a lapse of time amounting to about one hour, during which one generatios of division may occur (Chain and Duthie, 1945; Schuler, 1945). That of streptomycin is immediate: under favourable conditions it begins within one minute and may be, far advanced in ten minutes. So far as I am aware, no other bactericidal agent having so rapid an effect is dependent on a nutrient medium for its efficacy. This peculiar behaviour will have to be taken into account ip any hypothesis about the mode of action of streptomycin.

It was not considered necessary to study the effect of $p \mathrm{H}$, since it has been amply demonstrated by Abraham and Duthie (1946) that alkalinity $(p \mathbf{H} 8.0)$ favours the action of streptomycin, whereas on the acid side of neutrality (e.g., $p H$ 6.0) its activity is much diminished.

\section{Effect of Bacterial Numbers}

That the size of the inoculum affects the concentration of streptomycin required to inhibit growth has been shown by May, Voureka, and Fleming (1947), Berkman, Henry, and Housewright (1947), and Lenert and Hobby (1947). The dependence of bactericidal action on the same factor was observed by Strauss (1947). It was clearly of interest to determine the effect of inoculum size on bactericidal action under the conditions of the present experiments. Broth culture of Staph. aureus was spun down and resuspended in one-tenth of its original volume, this' suspension and three decimal dilutions of it being added to fresh broth containing $200 \mathrm{\mu g}$. of streptomycin per $\mathrm{ml}$. 
These mixtures were maintained at $37^{\circ} \mathrm{C}$, viable counts being made as usual (Fig. 6). The mixture with an initial count of the order of tens of millions was sterilized in two hours, as had repeatedly been observed before. Those ếntaining tenfold lower bacterial concentrations were sterilized in 30 minutes; that containing the highest bacterial concentration was not sterilized at all, the count falling by over $99 \%$ in 30 minutes and then remaining stationary for the remainder of the experimental period (eight hours). This experiment was repeated several times with different concentrations of both streptomycin and bacteria, always with the same type of result. The absolute concentration of sireptomycin is not the determining factor; it is the relation between that concentration and the numbers of bacteria. It appears that a given concentration of streptomycin can kill only a population of a certain density; if more are present some will survive.

Several possible explanations of this unusual finding bave been explored with negative results. Subcultures from surviving bacteria were retested by the same technique and found not to display any markedly increased resistance.

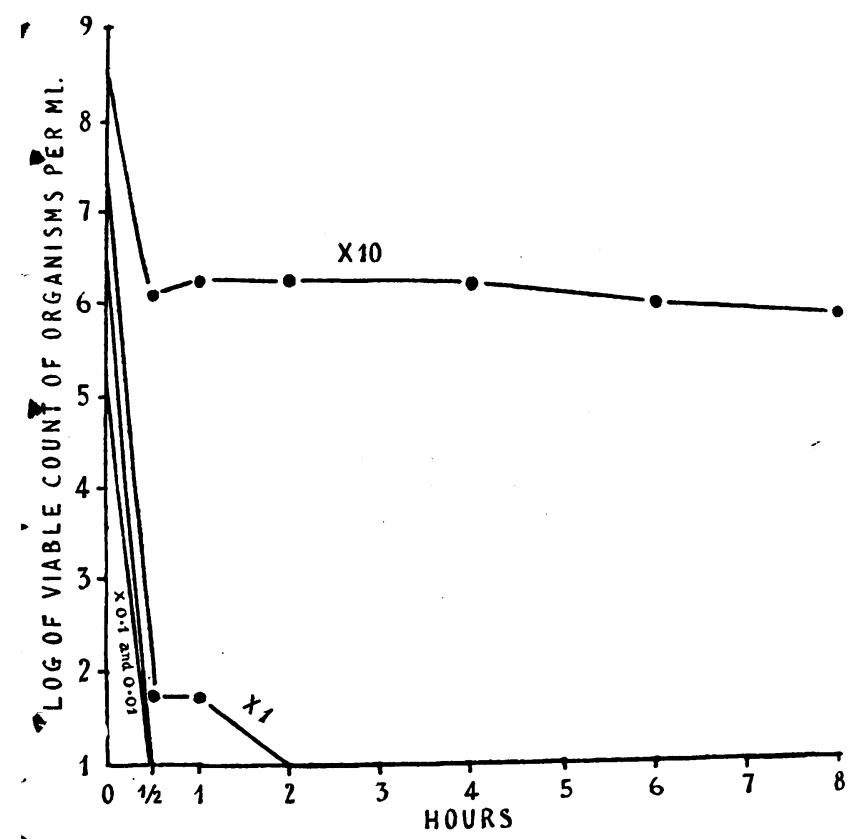

- FIG. 6.-Rate of death of Staph. aureus in broth containing $200 \mu \mathrm{g}$. of streptomycin per ml. at $37^{\circ} \mathrm{C}$.: inoculum of four different sizes $-\times 10,1,0.1$, and 0.01 of broth culture.

The streptomycin is not inactivated by an excess of bacteria; when these are removed and fresh culture of either Staph. aureus or Bact. friedländeri is added its bactericidal activity is undiminished. The presence of additional dead bacteria does not prevent the killing of living ones, provided the numbers of the living are within the capacity of the streptomycin concentration used.

4 Despite the apparently normal streptomycin sensitivity of cultures derived from survivors in such experiments the suspicion remains that a greater resistance possessed by a small proportion of cells in a culture must account for survival. It appears that no culture is homogeneous from this standpoint: Klein and Kimmelman (1946) have shown in the case of dysentery bacilli, and Alexander and Leidy (1947) in that of $\boldsymbol{H}$. influenzae, that an enormous inoculum will yield growth in a medium containing $1,000 \mu \mathrm{g}$. of streptomycin per $\mathrm{ml}$, indicating that one cell in some billions is resistant even to this concentration. The Oxford - strain of Staph.aureus behaves similarly ; a heavy inoculum (about 500,000,000 living cells) produced hundreds of colonies on agar containing 10 or $20 \mu \mathrm{g}$. of streptomycin per $\mathrm{ml}$., and 16, 2 , and 1 colonies respectively on agar containing 50, 100, and $200 \mathrm{ig}$. per $\mathrm{ml}$. It seems likely that this is only another aspect of the same phenomenon as survival in tests of bactericidal action, although the present experiments have not proved this. Further observations are desirable both on the effects of the ratio weight of streptomycin/bacterial numbers on bactericidal action and on the properties of cells surviving under such conditions.

\section{Clinical Applications}

It is generally assumed that parenteral streptomycin treatment has only a bacteriostatic effect, but the concentration attained in the blood for a time after a single dose may exceed $30 \mu \mathrm{g}$. per $\mathrm{ml}$., and this may well be bactericidal. Lower concentrations than this, according to Smith and Waksman (1947), will kill Myco. tuberculosis in vitro. The present tendency in the U.S.A. is to administer the drug only twice daily for the treatment of tuberculosis-a proceeding which does not maintain a constantly bacteriostatic concentration in the blood. Feldman (1946), treating tuberculosis in guinea-pigs, found that doses given once, twice, or four times dailỷ, or four times daily only during alternate weeks, had an "essentially equal efficacy." These otherwise anomalous findings could be explained by assuming that each dose actually kills many of the more susceptible bacilli which are accessible and actively multiplying at the time of its administration.

The fact that higher concentrations are more rapidly bactericidal has an important bearing on local treatment. Of this there are various forms, including intrathecal injection in meningitis, application to infected surfaces, and the treatment of urinary-tract infections. Streptomycin, like penicillin, is excreted in the urine, where it attains a high concentration. If its effect in vivo parallels that here described in vitro, susceptible bacteria should disappear rapidly from the urine soon after excretion has begun. In fact they do. In a number of patients receiving $0.5 \mathrm{~g}$. $(500,000$ units) of streptomycin four-hourly for the treatment of long-established and otherwise resistant urinarytract infections due to Bact. aerogenes, Bact. coli, or Ps. pyocyanea a series of specimens has been obtained at short intervals during the early stage of treatment and cultivated quantitatively. A viable count which is usually several hundred millions per $\mathrm{ml}$. before treatment falls to a few thousands two hours after the first dose-i.e., even before excretion has become maximal. After six, eight, or twelve hours, if treatment is going to succeed, the urine is completely sterile. If treatment is to fail, specimens continue to yield counts of a few hundreds or thousands per $\mathrm{ml}$. until the second day, when there is a sharp rise and the organism is found to be already much more resistant. It seems as if the issue is settled one way or the other within 24 hours or less. It also appears that an exceedingly brief period of treatment may suffice: in our experience apparently permanent cures of long-standing infections have been achieved by giving only six, four, or even three $0.5-\mathrm{gm}$. doses. Whether so small a total dose is always advisable only further experience can show. If so, the economy secured is an obvious advantage

\section{Conclusions}

1. Streptomycin is bactericidal. The rapidity and extent of its bactericidal action depend on: $(a)$ concentration-high concentrations having an exceedingly rapid effect : (b) temperature ; $(c)$ medium, the effect being exerted in all nutrient media, including certain body fluids, but only to a slight extent in non-nutrient media; $(d)$ the size of the inoculum, a small population being destroyed rapidly, whereas a proportion of a large one survives. 
2. It seems possible that the therapeutic effects of streptomycin are due to bactericidal rather than to bacteriostatic action. This is certainly so when high concentrations are attained locally, as in the treatment of infections of the urinary tract.

The streptomycin used in this work (streptomycin hydrochloride Merck) was supplied for studies in this hospital by the Streptomycin (Non-tuberculous Conditions) Clinical Trials Committee of the Medical Research Council, to whom I express my thanks. I am indebted for valuable technical assistance to Miss P. M. Waterworth.

\section{REFERENCES}

Abraham, E. P., and Duthie, E. S. (1946). Lancet, 1, 455.

Alexander, Hattie E., and Leidy, Grace (1947). J. exp. Med., 85 329.

Berkman, S., Henry, R. J., and Housewright, R. D. (1947). J. Bact., 53. 567.

Chain, E., and Duthie, E. S. (1945). Lancet, 1, 652.

Feldman, W. H. (1946). Trans. Stud. Coll. Phys. Phila., 14. 81.

Garrod, L. P. (1945). British Medical Journal, 1, 107.

Hamre, Dorothy, Rake, G., and Donovick, R. (1946). Proc. Soc. exp. Biol., N.Y., 62, 25.

Hegarty, C. P., Thiele, Elizabeth, and Verwey, W. F. (1945). J. Bact., 50, 651 .

Helmholz, H. F. (1945). Proc. Mayo Clin., 20, 357.

Klein, M., and Kimmelman, L. J. (1946). J. Bact., 52, 471.

Lenert, Tulita F., and Hobby, Gladys L. (1947). Proc. Soc. exp. Biol., N.Y., 65, 235.

May, J. R., Voureka, A. E., and Fleming, A. (1947). British Medical Journal, 1, 627.

Miles, A. A. (1937). Bull. Path. Bact. Lab. Assist. Ass., 3, 144.

Report (1946). J. Amer. med. Ass., 132, 70.

Schatz, A., Bugie, Elizabeth, and Waksman, S. A. (1944). Proc. Soc exp. Biol., N.Y., 55, 66.

Schuler, W. (1945). Schweiz. med. Wschr., 75, 34.

Smith, Dorothy G., and Waksman, S. A. (1947). J. Bact.. 54, 253

Strauss, E. (1947). Proc. Soc. exp. Biol. N.Y., 64. 97.

\section{CALCIFEROL IN THE TREATMENT OF CUTANEOUS TUBERCULOSIS}

BY

\section{G. D. POWELL, M.B.}

P. R. PEARsall, M.B.

Late House-Physicians to Skin Department. Charing Cross Hospital

AND

J. E. M. WIGLEY, M.B., F.R.C.P.

In Charge of Skin Department, Charing Cross Hospital

The value of calciferol in the treatment of lupus vulgaris is now generally known. Its mode of action is still a matter for speculation, and is likely to remain so until more serial observations upon cases undergoing this treatment have been made. This report describes a series of such cases treated at Charing Cross Hospital.

The advantage of calciferol over previous methods, with the results of which it seems to compare most favourably, is almost as much a social and economic as a medical one. That a large number of man-hours are saved by patient: taking a drug by mouth rather than attending a department for heliotherapy, etc., for many hours a week is obvious. In the present need for maximum effort and full employment this is a factor of considerable importance, and does not seem to have been sufficiently stressed.

This method of treatment seems to have started on both sides of the Channel at about the same time, and similar results were reached quite independently, which seems to us to add great value to these conclusions. Charpy (1943), in France, Fanielle, in Belgium, and Dowling and Prosser Thomas (1946), in London. appear to share the honours of being the pioneers in this treatment.

For the sake of brevity the cases are reported in tabular form, and those of special interest are referred to separately

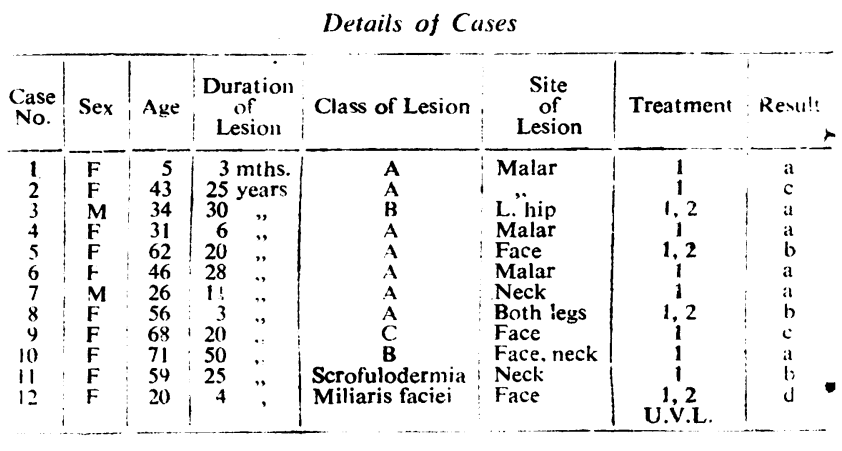

Key to Table

Class of Lesion (the Typical Nodules were of course Present in All Cases)

A. Lesions less than 4 in. (10 cm.) in diameter. No deformity produced by scarring.

B. Lesion greater than 4 in. in diameter; scarring may be exten-, sive but no disabling deformities present

C. A severe lesion producing extensive scarring and disabling deformities-e.g., ectropion or destruction of nasal cartilages.

\section{Treatment Groups}

1. Calciferol 50,000 units with added calcium thrice daily (" high potency osteiin" tablets).

2. Calciferol, either in pure alcoholic solution or in oily solution (" sterogyl"), 600,000 units per mi. twice weekly.

(a) Lesion clinically healed.

$$
\text { Result Groups }
$$

(b) Lesion very much improved, but one or two possible foci of activity still remaining.

(c) Progress of lesion arrested ; "minimal favourable response."

(d) No apparent response; lesion continuing to progress.

\section{Discussion of Results}

The twelve cases reported (see Table) have been under treatment for nine months or longer. Six were cured, three were very much improved, two have shown very little improvement, while one has shown no response to treatment.

These figures may be compared with the results obtained by Dowling and Prosser Thomas (1946) up to December, 1945-18 cured, 9 much improved, and 5 somewhat improved-also with those of Kusk? (1946) at Berne-50\% excellent, $20 \%$ arrest of lesion, and in the remainder a "minimal favourable response." (The assumption that this last group corresponds to result group " $c$ " in our table of results is our own.) Two other series which give figures for results are those of Dowling. Macrae, and Jones (1946) with 20 cases and $14(70 \%)$ recoveries, and of Dr. Emrys Jones, of Cardiff, who had II cases with 16 " cleared" $(89 \%)$.

Thus in some 82 cases we find $54(66 \%)$ which have healed under the influence of calciferol, and it is probable that with further treatment this figure will be higher still. It must, however, be remembered that the Finsen Institute in Denmark claimed 735 cures out of 975 cases $(75 \%)$ between 1914 and 1923 using methods other than the administration of large doses of calciferol.

It is probably safe to assume that about $60 \%$ of cases of lupus vulgaris in this country at this time may be cured by calciferol therapy alone (the reason for qualifying this statement is discussed on p. 388). It is of interest to note that streptomycin has been tried out in America on cases with lupus vulgaris, but the results have so far not been as successful as with calciferol.

\section{Two Cases of Special Interest}

Case 10.-This patient complained of flatulence, sickness, and diarrhoea after taking one "ostelin" tablet thrice daily for 14 days. She was told to continue with the tablets unless the sympioms got worse, when she was to stop taking them and report to 